\title{
The Localization Model of Chinese Government's Governance in the New Era
}

\author{
Gao Denghui, Wei Shuyan \\ Northeastern University, School of Humanities and Law \\ Shenyang 110169
}

\begin{abstract}
From a comprehensive government to a serviceoriented government, the governance model of the Chinese government has undergone many adjustments. In this gradual and continuous transformation process, the ideas, methods, structure, strategy and other elements of government governance have been adjusted to varying degrees, and the internal and external factors have also played a role at the same time. Due to the new requirements of the government reform in the New Era, the government must further improve itself, and form a multidimension compound governance model. The multi-dimensional government should be law-based, follow a variety of values and implement differential treatment according to the domain and hierarchy. In order to realize this innovative governance model, the government needs to cooperate with the ruling party, the national people's congress, other state institutions and the public.
\end{abstract}

Keywords-Government Governance; Government Governance Model; Localization Model; Multi-dimension Compound Governance Mode

\section{INTRODUCTION}

Government governance is the governance of public affairs by the government, which involves the arrangement and operation of the basic system of government, including the concept, structure, mode and process of government governance. Government governance model refers to the relationship between various governance systems and mechanisms, which is an organic framework and system including government governance concepts, methods, tools, structures and other elements.

\section{THE Proposal of the Localization MODEL}

The localization model was born in the unique Chinese process. In the early days of New China, the Chinese government formed the "all-round" model in the process of managing the country and resuming development. The model was influenced by the feudal history and the post-war national conditions, and has affected China for more than 20 years. After 40 years of reform and opening up, the all-round highly centralized government has gradually shifted to a decentralized modern government. "Building a service-oriented government" has become an important goal of the administrative system reform [1](p32).At present, with the socialism with Chinese characteristics entering the new era, the conditions, objectives and tasks of government governance have changed significantly, and the government reform has stood at a new logical starting point. In the new era, the development of productivity has shifted from focusing on "factors" and "investments" to focusing on "innovation", which has provided the driving force for government governance innovation. The major social contradictions in the new era embody the qualitative changes that have taken place in the people's needs and social production, which promote the change of government governance. New governments must be equipped with new capabilities to cope with rising demand.

The localization model was born in Chinese complicated and changeable national conditions. Historically, the government reform has always been in a gradual and dynamic change, and the change of governance model is a dynamic process that constantly adapts to external changes. The reform of government governance model is guided by the subjective understanding of national leaders and influenced by the national historical tradition. At the same time, it coincides with the changes of economic system, social contradictions, international environment and other factors. In the new era, the ruling party has made a top-level design to deepen the reform in an all-round way, which is the greatest driving force to promote the reform of government governance. At the same time, the governance crisis that exists in the development of economy, society, culture, ecology and the government itself also forces the government to reform and innovate. Of course, the growing maturity of social development, the increasing participation of the public and the growth of social organizations have also accumulated many positive factors for the reform of the government.

The new era is faced with new tasks. The "new" of the government is first reflected in the "new" of the mind. The government should be good at absorbing new things and let the mind enter into the new era with the body. The "new" of the government in the new era is embodied in the "new" method, and the government should combine the "high" and "low". On the one hand, the government can study the theory of governance thoroughly, and on the other hand, it can grasp the reality situation clearly, so as to achieve a thorough understanding and practice in the combination. Politics and academia are constantly seeking better government governance. And this paper proposes a multi-dimension compound governance model based on the local characteristics for advice. 


\section{ThE Position OF THE LOCALIZATION MODEL}

The orientation of Chinese government's further reform is the competent government. "The competent government refers to the government that its managers can transform their wishes and public good will into public policy through administrative activities and effectively implement it to achieve government's goals. It is helpful to realize the modernization of government, promote the sound development and progress of the domestic economy, politics, society, culture and ecological environment, and enable the state and local to maintain certain advantages in the international competition.[2](p106-115)" "Decision of the CPC Central Committee on Several Important Issues of Deepening the Reform in an All-round Way "clearly stipulates that the ability of governments at all levels to perform their duties should be strengthened. Therefore, "the future government to meet the modern standard should adhere to the principle of the ruling party, give up its power standard, balance the power of the government and the political party, the government and the society. The future government should set up a set of principles of democracy, the rule of law, fairness, service, responsibility, integrity and efficiency in accordance with the core values of socialism and the basic ethical principles of public administration [3].(p144-148)"

The competent government is the target of government construction and the reality basis of government governance model reform. However, the competent government does not mean that administrative power is not bound. The operation of executive power must have legitimacy, and must be constrained by the rule of law and the responsibility system. A good modern political system should consist of three elements: the strong state (good government), the rule of law and the responsibility system [4] (p283).These three factors complement each other and work together to serve the goal of state modernization. The healthy development of China in the future needs to fully implement the strategy of "rule by law", which urges the government to promote the work by way of rule of law so that "legal duties must be done and illegal duties are not allowed [5]. (p42-46)""Put the power into the cage of the system", with the responsibility system to shape a good government, to achieve a balanced unity of government power, the rule of law and accountability. This can not only guarantee the government administration of good governance, development, stability and security functions, but also inhibit the government's administrative arrogance, so as to optimize the government governance model and promote the grand blueprint for the modernization of national governance.

\section{THE CONTENT OF THE LOCALIZATION MODEL}

The localization model of Chinese government governance in the new era should be the multi-dimension compound governance model adapted to the complex national conditions, which emphasizes the multidimensional combination of government governance value and advocates the differentiated governance according to the region and level. The details are as follows:

First, the aggregation of multi-dimension value orientation, which is based on the core values of socialism demands, advocates the values of democracy, civilization, harmony, freedom, equality, justice and the rule of law, inherits the principles of service and supervision that have been constantly put forth in the government reform, absorbs the classical principle of honest value in ancient political culture and the open and transparent value in the governance of western countries, to realize the aggregation of the advanced value. The government should abandon the value orientation of emphasizing efficiency, emphasizing governance and belittling democracy, and realize multi-dimension value orientation in government governance.

Second, the government advocate the rule of law as the way of governance. In the rich management practice, the government has formed a variety of management methods, which some of them are habitual and efficient ways, such as special governance and management method. However, these governance modes have a certain conflict with the basic principles of the modernization of national governance. Therefore, the government must adjust and improve various governance modes, and implement the rule of law-based governance mode. It is a well-known way of governance in modern countries, and it is also the foundation and guarantee for the harmonious and sustainable development of Chinese society.

Third, the government governs according to the different regions and fields. This includes two meanings. One is to implement the corresponding governance model in the field of government governance, such as the government itself, economy, society, ecology and other fields. The two is to implement the corresponding governance model according to different regions. For example, the corresponding governance models in the eastern and western regions are implemented in accordance with the actual economic and social development. The details are as follows:

In the field of government management, the government should adopt a compound governance model which combines the bureaucratic autonomy model with the power supervision model. The bureaucratic autonomy model is the model of government self - governance, which is realized by means of administration, rule of law and accountability system. The supervision model focuses on strengthening the power supervision of the party and the national people's congress to the government, changing the reality of the virtual supervision of the national people's congress, improving social supervision, establishing the system channels of public supervision in the network society, and optimizing the governance model to achieve the goal of "good governance". 
In the economic field, the government should adopt the governance model of paying equal attention to market rule of law and government supervision. The government should promote the rule of law, ensure the market mechanism dominated and moderate government's regulation, supervision, service in parallel. Economic development should not only guarantee the market's invisible-hand position to allocate resources, but also properly serve the government's tangible role in a timely manner to manage the market failure and promote the orderly and healthy development of the market.

In the field of society, the government should adopt a cooperative governance model. The government should carry out democratic and cooperative governance, provide a platform for citizens, enterprises and social organizations to participate in governance, respect and protect citizens' right to participate fairly, and establish effective institutional channels for citizens' participation.

In the cultural field, the government should adopt the rule of law governance model. For a long time, the government has adopted the model of "sole rule" and "rule by man" in the cultural field. In the future, the governance model in the cultural field should be changed from a people-based model to a legal model, and from the sole governance model to an open model, so as to promote the prosperity of Chinese culture and provide more and better cultural environment for the socialism with Chinese characteristics.

In the field of ecology, it is advisable to adopt a holistic governance model. The government should implement the "ecological co-governance" model of equal cooperation between government, market and society so that both enterprises and social organizations become the backbone of ecological management. The government should speed up the formation of a professional and scientific system of ecological civilization and reshape our ecosystem in the legal framework [6] (p107-114+2).

In addition, the government should consider the regional differences between the east, the middle and the west of China, and implement the governance model with different characteristics. In the economically developed eastern region, the government is the main body of governance, which guides commercial organizations, social organizations and citizens to participate in governance. The party and the government should give equal status to the other subjects and advocate the cooperative governance model. However, the degree of economic and social development in the central and western regions is not as good as that in the east, and the development scale and capacity of industrial organizations and social organizations are weaker than these in the east. So the participatory governance model is more appropriate for the middle and west in which the government is the main and the society is supplemented.

Fourth, the government conducts affairs based on the characteristics of different levels. The central and provincial governments can implement a guided governance model that provides public policy guidance and public financial support. At the municipal level, the government could implement a "semi-guide + semi-implementation" combined governance model. On the one hand it guides the lower level government to implement the higher level government's policy; on the other hand, it should provide public services for urban residents and conduct market supervision and social conflicts. At the grassroots level, the county and township governments mainly accept the leadership of higher-level governments and should implement practical governance model.

In short, the multi-dimension compound governance model aims to achieve a holistic, systematic and synergistic match between the government reform and the development of economic, society, culture and ecological system, and to achieve coordinated governance among multiple subjects including government, enterprises, social organizations and citizens with the goal of promoting state governance towards modernization.

\section{THE REALIZATION PATH OF THE LOCALIZATION MODEL}

The multi-dimension compound governance model aims to promote the modernization of national governance according to the characteristics of Chinese economic, social, cultural, ecological and other fields, and the regional and hierarchical differences. To truly realize the government governance model with multi-dimension value and various governance models, it is impossible for the government alone to do what needs the joint efforts of the ruling party, state authorities, other national agencies and the public.

\section{A. Adhere to the correct leadership of the ruling party}

The ruling party is the core leadership in the development and progress of our country and the key driver of innovation in government governance. Facing the background of economic transition and social transformation under the influence of globalization, the ruling party must be able to grasp the overall situation of development, lead the implementation of national governance modernization strategy, and promote the reform of government governance model since this is an important part of realizing the modernization of state governance.

To promote the government reform, the ruling party should start from the following aspects:

First, it is necessary to reform and improve the party's leadership system and mechanism and adhere to the overall leadership of the party to the people's Congress, the government and other state organs. According to the spirit of the 19th Congress, the party is the leader of the national governance. We should improve the party's ability to grasp the direction, seek the overall situation, set policies and promote reform, so as to promote the government's reform and innovation. It is the basis and prerequisite to build a clean government by adhering to the strict administration of the party, purifying the political ecology of the party and punishing corruption.

Second, the party should adhere to the rule of law in an allround way and continue to promote the construction of democracy and the rule of law. The core of the modernization of national governance is democratic governance and rule-oflaw governance, and the key to promoting democracy and rule of law lies in the party, which is the premise of promoting 
government administration according to law and democracy, as well as the premise of protecting citizens' right to know, participate, express and supervise. The political party solve the problem of governance failure caused by the interference of interests through legal means and realize the government's effective governance in many fields.

Third, the party should promote the construction and innovation of the service-oriented government. It is the inevitable trend of cleaning up the officialdom by strictly governing the party in accordance with the law, using the system to govern lazy government and curbing corruption. It can effectively guide the government officials to strengthen the legal consciousness, and perform according to law strictly. The party should guide the government to abandon the inertial thinking that the power and regulation are paramount and let the party members and cadres establish the power and service view of administration for the people. The party should strengthen the supervision over the behavior of the government and its officials, increase the cost of violating the discipline, reduce the incidence of offside and vacancies, guide the government to accept social supervision and encourage it to solve the contradiction between the growing needs of the people and the inadequate development.

\section{B. Improve the state's legislative quality and power supervision}

The government, as the executive organ of the state authority, is created by the authority, responsible for it, and supervised by it. To improve the government governance model, the state authority should start from the following three aspects:

First, the state authority should improve the quality of legislation and solve the problem of the legalization for the government's interests. The government should carry out public administration according to the legislation of the people's congress. The good law is not only the basis of good governance, but also the guarantee of the modernization of national governance. The NPC must constantly improve the quality of legislation and timely amend outdated legal provisions to provide a legal basis for government governance and change the status of "governance by policy" to "rule by law". In addition, the National People's Congress also has to improve its own working mechanism, speed up the legislative process and solve the problem of no evidence under the law due to the fast-changing environment.

The second is to improve the supervision of power. As the highest organ of state power, the NPC has the power to supervise the government. Through the budget and final accounts, the authority supervises and checks whether the government abuses power and whether it is honest or clean. Through the inspection of law enforcement, the authority oversees whether the administrative organs carry out the state constitution and the law faithfully, and whether the administrative act is lawful. In short, the NPC must strengthen its own capacity of legal supervision and promote the reform and optimization of the government governance.

Third, it is necessary to adjust the provincial administrative division according to the actual situation. The provinces in the west of China are too large to manage. The NPC should study and adjust the system of administrative divisions based on their responsibilities and powers from the perspective of national safety management and administrative effectiveness.

\section{Promote self-reform of the government.}

The development of things is influenced by both internal and external factors, and the government's own subjective initiative plays a key role in the reform and perfection of government governance model. The government should proceed from the following aspects:

First, the government should reshape the values of governance. Idea is the guide to action. It's necessary for the government to rebuild the values of governance based on the values of socialism with Chinese characteristics and in accordance with the requirements of national modernization. The government's original concept of governance emphasizes efficiency, which fails to attach equal importance to democracy, the rule of law and fairness. The reform of governance requires that the government must change the monotonous concept of efficiency and promote the multi-dimension values.

Second, the central government should optimize the organizational structure of governance, integrate the three elements of organization, function and power, and solve the problem of excessive level and responsibility of the Chinese government. The organizational structure should be transferred to the flat pattern, and the administrative level should be reduced and the organization should be adjusted according to the provinces, cities and counties. In the city, the administrative power of the streets can be returned to the municipal government, and the administrative power of the residents belongs to the community to cancel the street level. In the countryside, the township level can become the township government agency of the county government. In order to change the setting principle of the upper and lower sides, the central government should further promote the reform of the major system, and the local government should set up the department according to the management, and do well to connect with the superior departments.

Third, the government should improve the institutional mechanism. It is the first choice to improve the selection and training system for cadres. The government needs to share responsibility with the party and scientific public decisionmaking mechanism. In addition, information system and intelligence support system are important assistants in scientific decision-making. The system of investigating major decision responsibility, examining the legitimacy of policy and public finance are also the important means of governance. 


\section{Encourage social participation}

Social participation is an important way to promote cooperative governance and promote the modernization of state governance. Social participation should proceed in the following three aspects. First, the multi-interest demands of society promote the government reform. In order to solve the social contradictions involving their own interests, the public strives to win the attention of the government through mass media, such as the Internet media and so on. Through the power of public opinion, we should push forward the reform and improvement of the government governance model, promote the openness of government affairs and promote the administration according to law. Second, the social organizations promote the construction of service-oriented government. The huge public demand for public services is the driving force for the government to continuously improve its services. A large number of social organizations share the pressure of the government to provide public services independently. The government can reduce administrative costs and improve administrative efficiency through the purchase of services. Third, the public supervises the government behavior. Corruption of officials, abuse of power, and administrative inaction were frequently exposed, and the "Chaoyang people" was once a model of supervision. The governance of official corruption and the reshaping of political ecology depend on the system construction of our party and the active participation of the masses of citizens.

\section{CONCLUSION}

It needs profound changes of the party and national governance model to promote the modernization of national governance. In the new era, it is an essential choice to establish the multi-dimension compound governance model for complying with the major policies of the ruling party to deepen reform, overcoming the bureaucratic inertia and vested interests, improving the government administrative ability and service level, solving the governance problems and social contradictions, and responding to the public demands. It is also an important measure to discard the traditional thinking of the government, promote the development of national economy and society, and improve the government's ability to meet domestic and foreign challenges. The most important thing is that the joint efforts of the ruling party, the state authority, the government and the public are the only way to promote the government reform.

\section{ACKNOWLEDGMENT}

Fund: The Key Project of the National Social Science Foundation of China "Study on the reform of Chinese government governance model under the influence of national governance modernization" (15AGL017).

Authors: Gao Denghui (1991 -), female, from Shandong Binzhou, Ph. D. candidate of Northeastern University, engaged in research on government governance. Contact: 18640366846, e-mail:1540358245@qq.com.

Wei Shuyan (1965 -), female, from Liaoning Beizhen, professor and doctoral tutor of Northeastern University, engaged in public policy, government governance and public crisis management.

\section{REFERENCES}

[1] Hu Jintao, Holding high the great banner of socialism with Chinese characteristics and striving to win the new victory of building a well-off society in an all-round way -- a report on the Seventeenth National Congress of the Communist Party of China [M]. Beijing: People's press, 2007:32. (In Chinese)

[2] Wei shuyan. Capacity-building and modernization of government governance in China[J/OL]. Journal of Guizhou party school, 2017, (6):106-115(2017-11-03)

http://kns.cnki.net/kcms/detail/52.5023.D.20171103.0926.028.html. DOI : 10.16436/j.cnki.52-5023/d.2017.06.014. (In Chinese)

[3] Wei Shuyan, Lu Wenling, Li Fuyu.Government governance modernization in China: balanced development of capability government, rule of law and accountability system [J]. Theoretical Investigation,2016,(5):144-148. (In Chinese)

[4] Francis Fukuyama.The origins of political order: from the human times to the French revolution [M].Translator Mao Junjie, Guilin: Guangxi Normal University press,2014:283. (In Chinese)

[5] Li Anlin. The basic strategy and path of the Chinese Communist Party in governing the country by law [J]. Academic Forum,2014,(10):42-46. (In Chinese)

[6] Zhao Cheng, Yu Ping.The choice of ways to construct the ecological civilization system [J]. Journal of Harbin Institute of Technology (Social Sciences Edition),2016,18(05):107-114+2. (In Chinese) 